\title{
A Case-Based Approach to the Development of Practice-Based Competencies for Accreditation of and Training in Graduate Programs in Genetic Counseling
}

\author{
Morris B. Fiddler, ${ }^{1}$ Beth A. Fine, ${ }^{2,5}$ Diane L. Baker, ${ }^{3}$ \\ and ABGC Consensus Development Consortium ${ }^{4}$
}

The American Board of Genetic Counseling ( $A B G C$ ) sponsored a consensus development conference with participation from directors of graduate programs in genetic counseling, board members, and expert consultants. Using a collective, narrative, and case-based approach, 27 competencies were identified as embedded in the practice of genetic counseling. These competencies were organized into four domains of skills: Communication; Critical Thinking; Interpersonal, Counseling, and Psychosocial Assessment; and Professional Ethics and Values. The adoption of a competency framework for accreditation has a variety of implications for curriculum design and implementation. We

${ }^{1}$ School for New Learning, DePaul University, Chicago, Illinois.

${ }^{2}$ Department of Obstetrics and Gynecology, Northwestern University Medical School, Chicago, Illinois.

${ }^{3}$ Department of Human Genetics, University of Michigan, Ann Arbor, Michigan.

${ }^{4}$ The Consortium includes Directors of established graduate programs in genetic counseling and members of the ABGC Board of Directors who participated in the Consensus Development Conference held in January 1994: Diane Baker (University of Michigan/ABGC); Bonnie Baty (ABGC); Joan Burns (University of Wisconsin); Debra Collins (ABGC); Virginia Corson $(A B G C)$; Beth Fine (Northwestern University/ABGC); Elizabeth Gettig (University of Pittsburgh); Verle Headings (Howard University); Jacqueline Hecht (University of Texas); Carl Huether (University of Cincinnati); Bonnie LeRoy (University of Minnesota); Joan Marks (Sarah Lawrence College); Anne Matthews (University of Colorado); Roberta Palmour (McGill University); Lorna Phelps (Medical College of Virginia); Kimberly Quaid (Indiana University); Joan Scott (ABGC); Ann Smith (ABGC); Helen Travers (ABGC); Judith Tsipis (Brandeis University); Ann Walker (University of California-Irvine/ABGC); Jon Weil (University of California-Berkeley); $S$. Robert Young (University of South Carolina); Randi Zinberg (Mount Sinai School of Medicine, New York).

${ }^{5}$ Correspondence should be directed to Beth A. Fine, Graduate Program in Genetic Counseling, Northwestern University Medical School, Ward Building 18-171 (W143), 303 East Chicago Avenue, Chicago, Illinois 60611. 
report here the process by which a set of practice-based genetic counseling competencies have been derived; and in an accompanying article, the competencies themselves are provided. We also discuss the application of the competencies to graduate program accreditation as well as some of the implications competency-based standards may have for education and the genetic counseling profession. These guidelines may also serve as a basis for the continuing education of practicing genetic counselors and a performance evaluation tool in the workplace.

KEY WORDS: genetic counseling; practice-based competencies; graduate program accreditation.

\section{INTRODUCTION}

Genetic counselor training at the master's degree level has evolved over the past quarter century into a multidisciplinary, integrated educational experience. Curricula have developed in response to advances in genetics and diagnostic technology. The recognition that genetic counselors must communicate medical, genetic, and technical information in a manner that takes into account the educational, psychosocial, ethnocultural, and economic dimensions unique to each client and family has also shaped the theory and practice of genetic counseling (Kenen, 1984). The current guidelines for designing, evaluating, and revising curricula and clinical training reflect definitions of the roles and responsibilities of genetic counselors that have evolved over the past 25 years. These guidelines were generated and reviewed at a series of conferences known as the "Asilomar meetings," held between 1974 and 1989 (Walker, et al., 1990).

The first step in accrediting genetic counselor training occurred in 1980 when the American Board of Medical Genetics (ABMG) established accreditation criteria for five subspecialty areas within the practice of clinical and laboratory genetics. The ABMG accreditation strategy for genetic counseling, while it incorporated some of the Asilomar recommendations, set requirements primarily for the clinical training sites affiliated with programs. In 1993, the $A B M G$ initiated a restructuring process which significantly altered the landscape of credentialing in clinical genetics (Epstein, 1992; Heimler et al., 1992). One direct outcome of this restructuring was the establishment of the American Board of Genetic Counseling (ABGC), a new accrediting and credentialing body whose primary functions are the education and certification of master's level genetic counselors (Restructuring Committee, 1992; Scott, 1993). Concomitantly, the genetic counseling profession faces the continuing challenges and opportunities being generated by advances in genetics and biotechnology, reorganization of healthcare services, and changes in allied health 
education. Therefore, it is necessary to formulate guidelines for the accreditation of graduate programs that allow for both flexibility across training programs and provide the capacity to measure the achievement of specific practice skills by trainees.

The ABGC recognized that restructuring presented an opportunity to reassess the design of extant accreditation guidelines and the approach to accreditation. A first step was to examine the accreditation practices of other professions. The ABGC analyzed a variety of accreditation methods, values, and beliefs and formulated a framework for the education of graduate students in genetic counseling. It elected to accredit entire programs, instead of only clinical training sites as had been the procedure under the $\mathrm{ABMG}$. The ABGC chose this integrative approach to accreditation standards to assure the public and prospective students of the availability of quality professional training (ABGC, 1993).

Since the inception of formal graduate education in genetic counseling in 1969, more than 20 university-based programs have been established. Each program has adopted its own approach to designing and implementing curricula guided by the general framework outlined in the Asilomar reports and the requirements of individual institutions. The Asilomar guidelines are primarily content-driven and consist of lists of required and recommended course topics and categorical types of clinical experiences. The ABGC recognized an opportunity to draw on the expertise and diversity among program directors to develop accreditation guidelines that could also define practice standards by articulating competencies embedded in the practice of genetic counseling.

\section{CONTEXT}

In January 1994, the ABGC Board of Directors, led by its Accreditation Committee, convened a Consensus Development Conference in Chicago, Illinois. The goal of the conference was to elicit input on the development of academic and clinical training criteria from genetic counseling graduate program directors, many of whom were also practitioners of genetic counseling, and expert consultants in education and accreditation. One objective for the meeting was the development of a draft set of practice-based competencies that could be further refined and ultimately serve as the basis for the Requirements for Graduate Programs in Genetic Counseling Seeking Accreditation by the American Board of Genetic Counseling (ABGC, 1996).

Several considerations led to the decision to move toward competencybased accreditation. First, by using a consensus method among educators and practitioners to collectively identify discrete clinical components of genetic 
counseling practice, the $\mathrm{ABGC}$ can hold the profession to a common set of expectations while still allowing flexibility in educational approaches and styles. Second, by defining the performance-based outcomes of education, programs are offered the opportunity to draw on the diversity of their experiences to design effective, practical learning activities for their students. The methods for facilitating learning could vary and change as a function of educational insights and innovations while the desired outcomes remain defined and consistent. The establishment of competencies derived from practice should help to promote state-of-the-art teaching methodologies, sound assessment measures, and clinical practice guidelines for practitioners at all levels of experience. Third, the development of competencies that are framed in terms of practice allows for integration of theory and application from the multiple disciplines that inform genetic counseling, thus fostering a holistic approach to learning. The competencies that students develop would be applicable to many professional circumstances. These competencies would encourage continued growth of individuals and the profession as new challenges are encountered in response to technological changes and scientific advances. Fourth, the competencies could be used to clarify graduates' expertise and abilities to future employers and granting agencies. Finally, a set of practicebased competencies can be part of the information available to the public that will demonstrate the professions' standards and accountability (ABGC, 1993).

A review of the literature on accreditation and consultation with experts in the fields of adult learning, allied health, and counseling psychology clearly revealed a growing trend toward defining educational objectives in terms of outcomes (Simmons, 1994; Lane and Ross, 1994; Lane et al., 1995). The Council on Allied Health Education Accreditation (CAHEA), recently reorganized as the Committee on Accreditation of Allied Health Education Programs, represents 27 allied health organizations. CAHEA officials view outcome-based (i.e., competency-based) accreditation as a paradigm shift which allows a field to capitalize on creativity within curriculum design, support different student learning styles and promote characteristics that are unique to individual programs. Outcome-based education is also an integrated approach which asks what each course or student experience is teaching and how it relates to practice in the profession. Use of competencies can foster evaluation methods for students that will more precisely measure the quality of activities they will be required to perform as practicing genetic counselors. The ABGC Board of Directors elected to join the growing trend in outcome-based accreditation while laying the groundwork for advancing the education of current and future genetic counselors. 


\section{METHODS}

The Consensus Development Conference was designed around a case-based, narrative process for identifying practice-based competencies (Fiddler and Alicea, 1996; Fiddler, 1995). An overview of the methodology adapted from critical incident techniques (Flanagan, 1954) and behavioral event interview strategies (McClelland, 1978) is presented here. Critical incident techniques focus on meaningful "real life" situations of an individual that offer insights into behaviors and attitudes. Behavioral event interviewing is a strategy that uses a set of questions that focuses on behaviors associated with various capabilities, yet limits interpretive conversation between the participants. These two approaches were integrated and modified for use in groups as a case-based narrative strategy. It provided a focus and structure to facilitate reflection and analysis while capturing the complexities, spontaneity, and interpretive nature of genetic counseling. Participants used their experiences with counseling techniques, case management strategies and teaching as a rich data source from which to extract practice-based competencies. The process, guided by one of the authors (MF), engaged the 24 participants in the steps summarized in Table I.

Table 1. Process for Developing Practice-Based Competencies

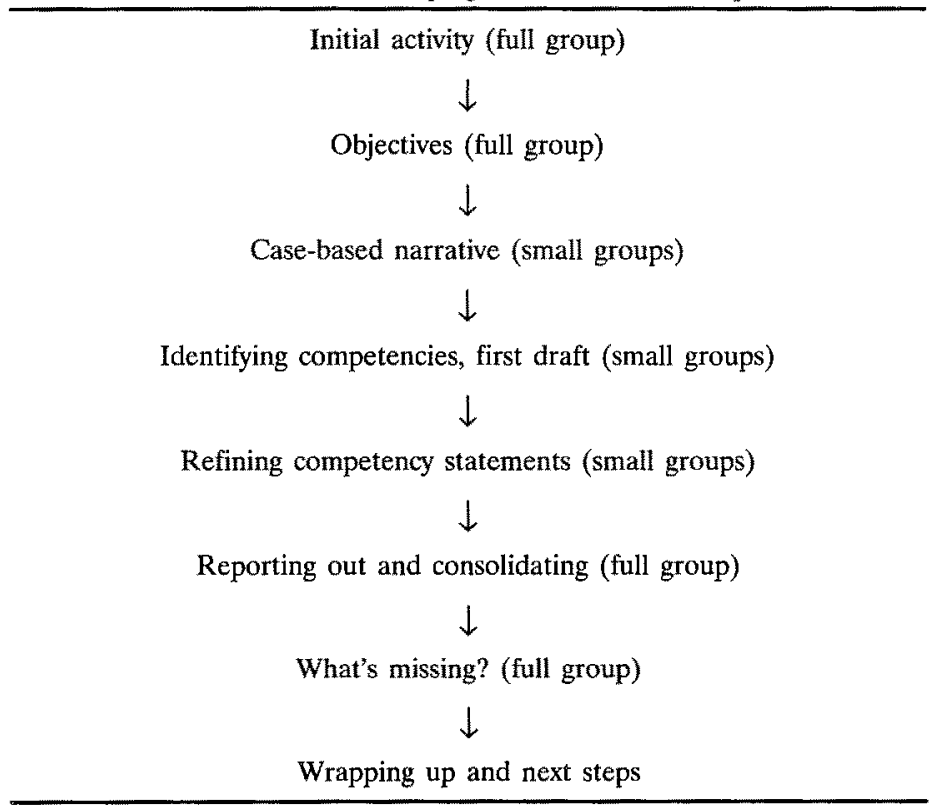


Initial Activity. The first activity brought participants together to consider, discuss, and document responses to the following question: "What do you think an entry-level genetic counselor should be able to do?" This exercise served as preparation for a step that would come near the end of the conference (the What's Missing? section).

Objectives. Conference facilitators provided an orientation to the concept of competency-based learning and education. They informed participants that the desired outcomes of the conference were to: (a) provide an opportunity to reflect on one's knowledge and experiences and frame both in a practice-based orientation, and (b) develop a draft set of statements that describe the competencies of qualified entry-level genetic counselors. We intentionally avoided a description of the sequence and purpose of the ensuing activities at the beginning of the workshop so that participants would not circumvent any of the steps, particularly the casebased narrative phase.

Case-Based Narrative (or Describing Genetic Counseling Encounters). Four subgroups with five or six participants in each were assigned one of the following genetic counseling contexts: advanced maternal age/prenatal diagnosis counseling; pediatric counseling; adult-onset counseling; or carrier screening counseling. We believe these contexts represent the majority of counseling experiences in the field and provide a rich and inclusive dataset. One to two people in each subgroup related, in a narrative format, a specific patient encounter from within the assigned context. The other members of the group listened and asked about specific behaviors, thoughts and language through questions phrased to clarify, not interpret the storytellers' case. The reports were not necessarily about "successful" genetic counseling cases, but rather informative interactions that conveyed a range of behaviors and skills reflecting a "typical" case. One group member recorded the narrative in detail.

Identifying Competencies in the Narratives. The subgroups analyzed their notes for the skills, knowledge, and attitudes reflected in the stories to generate as many competency statements as possible. The cases were "dissected" into incremental activities or functions necessary for case management. Participants used the general syntax of a competency statement in which the third person (student or genetic counselor) is understood and the format is to begin with the word, "can." For example, "Can elicit an appropriate and inclusive family history" (Fine et al., 1996). Special emphasis was placed on choosing verbs that reflected abilities or actions expressed in the narratives.

Refining the Competencies. Once a draft set was generated, the groups reviewed and edited each statement for clarity, completeness, and uniqueness; also, if members of the group could identify underlying or contributing 
areas of knowledge to the competency, the statement was extended into the form: "Can . . . based on an understanding of. ..." The participants explored the use of each draft competency for performance evaluation and revised the competency to address a single practice component.

Reporting Out. The full group reconvened to report the sets of statements from each subgroup. The facilitator of the session documented the statements on flip charts, occasionally probing for clarity of language and the extent to which one statement overlapped with another.

"What's Missing?" Next, the first full draft of a collective set of competency statements was near completion. Each member of the group examined the statements to identify deficiencies. Participants consulted their lists describing abilities of an entry-level genetic counselor (constructed in the "Initial Activity" phase) to supplement and complete with individual reflections, what had emerged from the group's effort.

\section{OUTCOMES OF THE NARRATIVE PROCESS}

Conference participants generated 52 draft competency statements, capturing the knowledge, skills, and attitudes reflected in the practice of genetic counseling. In the weeks following the conference, two of us (BF, DB) consolidated and further distilled this list of "raw" statements into 27 competencies through further analysis of the functions expressed in the statements. After circulating this list among the conference participants for feedback and recommendations, we considered and responded to the commentaries and further refined the set of competencies.

We organized the competencies into four categories or "domains" of genetic counseling practice. While we recognize that several of the competencies may fit under more than one domain, the rationale for the categorization was based on the analysis of themes among the competencies as well as experience with teaching and evaluating students during clinical training. For example, "Can elicit an appropriate and inclusive family history" was considered a communication skill, while "Can assess and calculate genetic and teratogenic risks" reflected critical thinking skills. A student could succeed at the former without necessarily succeeding at the latter skill. Thus, the competencies reflect a dissection of practice into components that can be identified, demonstrated, and evaluated within the clinical setting. We used information generated in the "Refining the Competencies" step, additional review by the ABGC Board of Directors, and the authors' own professional experiences to develop a supplementary set of "facets" to elaborate each competency statement. 
The final set of practice-based competencies of genetic counseling and the related introductory comments are an integral part of the document entitled Requirements for Graduate Programs in Genetic Counseling Seeking Accreditation by the American Board of Genetic Counseling (American Board of Genetic Counseling, 1996) and are provided in the accompanying article (Fine et al., 1996).

\section{ACKNOWLEDGMENTS}

The authors gratefully acknowledge the American Board of Genetic Counseling, Inc. for supporting the Consensus Development Conference. We also express our appreciation to Sharon Robinson and to Randy Gresham for his assistance with the manuscript.

\section{REFERENCES}

American Board of Genetic Counseling (1993) American Board of Genetic Counseling By-Laws.

American Board of Genetic Counseling (1996) Requirements for Graduate Programs in Genetic Counseling Seeking Accreditation by the American Board of Genetic Counseling, Bethesda, MD: American Board of Genetic Counseling.

Epstein C (1992) Organized medical genetics at a crossroad. Am I Hum Genet 51:231-234.

Fiddler MB (1995) Using Storytelling to Identify Practice-Based Competencies of Advising. Proceedings of The Alliance/ACE Conference, ERIC Clearinghouse.

Fiddler MB, Alicea M (1996) Use of a collective narrative process to articulate practice-based advising competencies. NACADA $J$, in press.

Fine BA, Baker DL, Fiddler MB, ABGC Consensus Development Consortium (1996) Practice-based competencies for accreditation of and training in graduate programs in genetic counseling. $J$ Genet Counsel, 5:113-121.

Flanagan J (1954) The critical incident technique. Psychol Bull 51:327-358.

Heimler AH, Benkendorf J, Gettig E, Reich E, Schmerler S, Travers H (1992) American Board of Medical Genetics restructuring: make an informed decision. Am J Hum Genet $51: v$-vii.

Kenen RH (1984) Genetic counseling: The development of a new interdisciplinary occupational field. Soc Sci Med 18(7):541-549.

Lane DS, Ross V (1994) Consensus on core competencies of preventive medicine residents. Am J Prevent Med 10:52-55.

Lane DS, Ross V, Parkinson MD, Chen DW (1995) Performance indicators for assessing competencies of preventive medicine residents. Am J Preventive Med.

McClelland D (1978) Guide to Behavioral Event Interviewing. Boston: McBer and Company.

Restructuring Committee (1992) Review and update on ABMG status. Perspect Genet Counsel $14(2): 1-3$.

Scott J (1993) ABGC incorporates. Perspect Genet Couns 15(1):1.

Simmons HL (1994) Critical challenges facing allied health accreditation: Pressures on accrediting bodies. $J$ Allied Health 23(1):23-28.

Walker AP, Scott JA, Biesecker BB, Conover B, Blake W, Djurdjinovic L (1990) Report of the 1989 Asilomar meeting on education in genetic counseling. Am J Hum Genet 46:1223-1230. 